\title{
Characterisation of electron beam melting process on Ti6Al4V in order to guide finishing operation
}

\author{
Adrien Dolimont* \\ Machine Design and Production Engineering Unit, \\ Faculty of Engineering, \\ University of Mons, \\ Place du parc, 20, 7000 Mons, Belgium \\ Email: adrien.dolimont@umons.ac.be \\ *Corresponding author
}

\section{Sébastien Michotte}

SIRRIS - Collective Centre for and by the Technological Industry, 26 Rue Auguste Piccard, 6041 Gosselies, Belgium

Email: sebastien.michotte@sirris.be

\section{Edouard Rivière-Lorphèvre and François Ducobu}

Machine Design and Production Engineering Unit,

Faculty of Engineering,

University of Mons,

Place du parc, 20, 7000 Mons, Belgium

Email: edouard.riviere@umons.ac.be

Email: francois.ducobu@umons.ac.be

\section{Charlotte de Formanoir and Stéphane Godet}

4MAT - Materials Engineering, Characterisation, Synthesis and Recycling,

Faculty of Engineering,

Université Libre de Bruxelles,

Avenue F.D. Roosevelt, 50 - 1050 Bruxelles (CP 165/63), Belgium

Email: cdeforma@ulb.ac.be

Email: sgodet@ulb.ac.be

\section{Enrico Filippi}

Machine Design and Production Engineering Unit,

Faculty of Engineering,

University of Mons,

Place du parc, 20, 7000 Mons, Belgium

Email: enrico.filippi@umons.ac.be 
Abstract: There is still a lack of standards in the fast growing Additive Manufacturing (AM) field and efforts are still required to improve parts reliability, consistency and quality. The aim is to define machining allowance for the Electron Beam Melting (EBM) process on Ti6Al4V, which still needs finishing step. Analysis on the dimensions obtained was carried out over a large number (110) of raw printed parts having the same geometry using a coordinate measuring machine (CMM). The geometric and dimensional tolerances were highlighted. A micro-geometrical analysis was also carried out to determine the roughness dispersion. A capability analysis was conducted to define the class of tolerance for EBM process. The results show that the Interval of Tolerances (IT) class is close to sand casting process for dimensional characterisation (IT15 or even IT12 if systematic errors are suppressed). This study is carried out in order to guide finishing operations occurring after AM.

Keywords: additive manufacturing; EBM; electron beam melting; surface roughness; metrology; finishing operation; interval of tolerance; capability; Ti6Al4V.

Reference to this paper should be made as follows: Dolimont, A., Michotte, S., Rivière-Lorphèvre, E., Ducobu, F., de Formanoir, C., Godet, S. and Filippi, E. (2015) 'Characterisation of electron beam melting process on Ti6Al4V in order to guide finishing operation', Int. J. Rapid Manufacturing, Vol. 5, Nos. 3/4, pp.320-338.

Biographical notes: Adrien Dolimont holds a Bachelor's degree in Engineering (2009) from the University of Mons and a Master's degree in Mechanics Engineering (2011) from the University of Mons. He is presently $\mathrm{PhD}$ student at Machine Design and Production Engineering Lab, Faculty of Engineering, University of Mons.

Sébastien Michotte holds a Master's degree in Materials Engineering (2000) and a $\mathrm{PhD}$ in Applied Sciences (2005) both from the Université Catholique de Louvain. He is currently Project Manager at Sirris: Fabrication by additive manufacturing techniques (mainly metals) for the aeronautic and aerospace sectors, such as Ti6Al4V by EBM. He has about 15 years of experience doing research in the field of materials sciences (electrodeposition, electroplating, vacuum coating techniques such as sputtering or e-beam deposition, electrical, magnetic, optical, thermal and mechanical properties of materials, in-situ stress measurement, cryogenic measurement, superconductivity, nanotechnologies). He has 40 publications in peer reviewed international journals.

Edouard Rivière-Lorphèvre received the Engineer degree in Mechanics in 2003 and his PhD in 2007. Since 2011 he is Lecturer at the Faculty of Engineering (FPMs) of the University of Mons (UMONS) in the Machine Design and Production Engineering Lab. His research interests are in the area of simulation of machining techniques and detection of instabilities in machining operations.

François Ducobu received the Engineer degree in Mechanics in 2007. He is Senior Research Assistant at the Faculty of Engineering (FPMs) of the University of Mons (UMONS) in the Machine Design and Production Engineering Lab where he achieved his $\mathrm{PhD}$ in the field of machining by removal of chips in 2013. His main works concern the numerical (finite elements) and experimental study of Ti6Al4V orthogonal cutting and the macro- to micro-cutting transition. 
Charlotte de Formanoir holds a Bachelor's degree in Engineering (2011) from the Université Libre de Bruxelles and a Master's degree (magna cum laude) in Chemical and Materials Engineering (2013) from the Université Libre de Bruxelles. She is presently PhD student at the 4MAT Department, Université Libre de Bruxelles. Her project is entitled 'Additive Manufacturing of Ti-6Al-4V Parts: From Microstructural Control to Architectured Materials'. This project is supported by the Fond National de la Recherche Scientifique (FRIA grant).

Stéphane Godet is Professor at the Université Libre de Bruxelles and Head of the 4MAT Department. He holds a Master's degree in Materials Engineering (1998-Magna Cum Laude) from the Université Catholique de Louvain and a $\mathrm{PhD}$ in Materials Engineering from the same university (2003). After a 2-year Post-doc at McGill University, he was appointed as Postdoctoral Fellow of the Fond pour La Recherche Scientifique together with a Return Grant from the Federal Scientific Policy. He became Assistant Professor at the Université Libre de Bruxelles in 2006 and is Professor since 2010. His main research interests are the link between processing parameters, microstructure development and mechanical properties in inorganic materials.

Enrico Filippi is Professor at the Faculty of Engineering (FPMs) of the University of Mons (UMONS) and head of the Machine Design and Production Engineering Lab since 2000. Before that date, he has held different technical and managerial positions in industrial companies (ACEC, Goodyear and Alcatel ETCA). During his career in the industry, his main research interests were: structural and thermal analysis, finite element techniques, noise and vibration measurement, modal testing, rotating machinery, earthquake design of equipment, pyroshock testing, vibration testing and packaging of aerospace electronic equipment. His current research interests are in the field of virtual manufacturing (machining processes, resin transfer moulding techniques).

\section{Introduction}

Additive Manufacturing (AM) technologies are a booming field (Monfort-Windels, 2013). The AM technology initially devoted to rapid prototyping for product visualisation has now proved for long its ability to produce real parts with the required mechanical properties. AM is widely used to produce biomedical, aerospace and rapid tooling parts (Vutova et al., 2010). This technology is also largely applied to the development of new products. The evolution of AM has permitted a shift from prototyping to the production of parts with good mechanical properties. The interest of AM technologies is that this kind of processes uses less material and produces less waste than traditional techniques and unlocks the design limitations unlike the other processes. The Electron Beam Melting (EBM) is one of them. EBM technology was developed at Chalmers University of technology in the late 1990s and commercialised by the Swedish company Arcam AB in the early 2000s (see www.arcam.com). This process is a layerby-layer process which allows to build fully dense metallic parts from powder particles. This is divided into five steps (Figure 1):

1 Definition of a CAD model (.stl file);

2 Pre-treatment to orient the part in the batch of fabrication and supports placement (to improve heat transfer); 
3 Slicing the part in a 2D-file (the electron beam works in 2D);

4 Manufacturing with the ARCAM printer;

5 Post-treatment of the part (sand blasting, supports removing, etc.).

Figure 1 Manufacturing cycle for EBM process (Farhat and Engel, 2012) (see online version for colours)

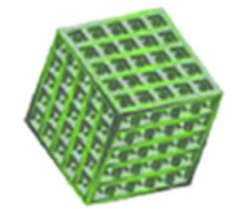

Basic data :

3D CAD model - input.STL file

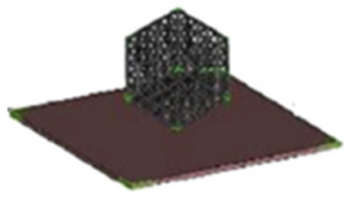

Pre treatment : Part orientation

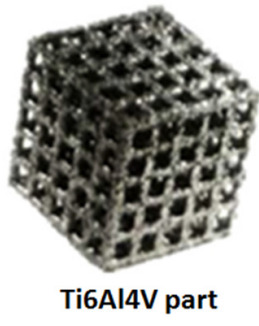

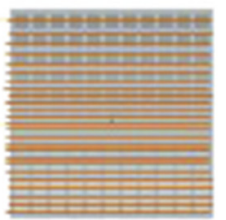

Pre treatment : 2D slicing file

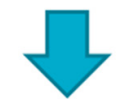

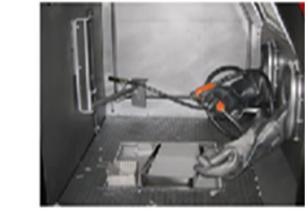

Post treatment :

Cleaning, coating, sand blasting, finishing
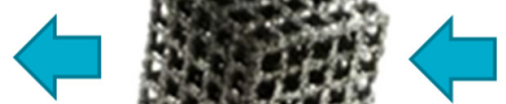

Manufacturing Arcam

2D layers successive addition

For the fourth step, the powder is fused by an electron beam layer-by-layer. The electron beam is generated by a tungsten filament and directed by 3 coils (Figure 2). This process occurs under controlled vacuum $\left(2 \times 10^{-3}\right.$ mbar of $\left.\mathrm{He}\right)$ to avoid reaction between reactive metal and atmospheric gases. The Arcam printer is building the part layer by layer, while using calculation to maintain a constant temperature of the surface being processed. This permits to minimise the internal stresses within the parts. The fusion is achieved in 3 steps:

1 The pre-heating: In this step, an unfocused electron beam is swept across the layer surface to maintain the powder at the desired temperature. The areas where subsequent melting will occur are prone to a higher heating and thus a higher sintering. This prevents the powder grains from detaching and being expulsed upward during the next melting steps.

2 The fusion of the contour: A focused electron beam melts the contours of the parts by first melting the outer perimeter and then by melting the inner perimeters that are concentric offsets of the first one.

3 The fusion of the core: The bulk of the part is then melted by using raster patterns. 
The most widely used material for the EBM Process is Ti6Al4V. This is the material used in this study with standard processing parameters.

Figure 2 EBM process (Mahale, 2009) (see online version for colours)

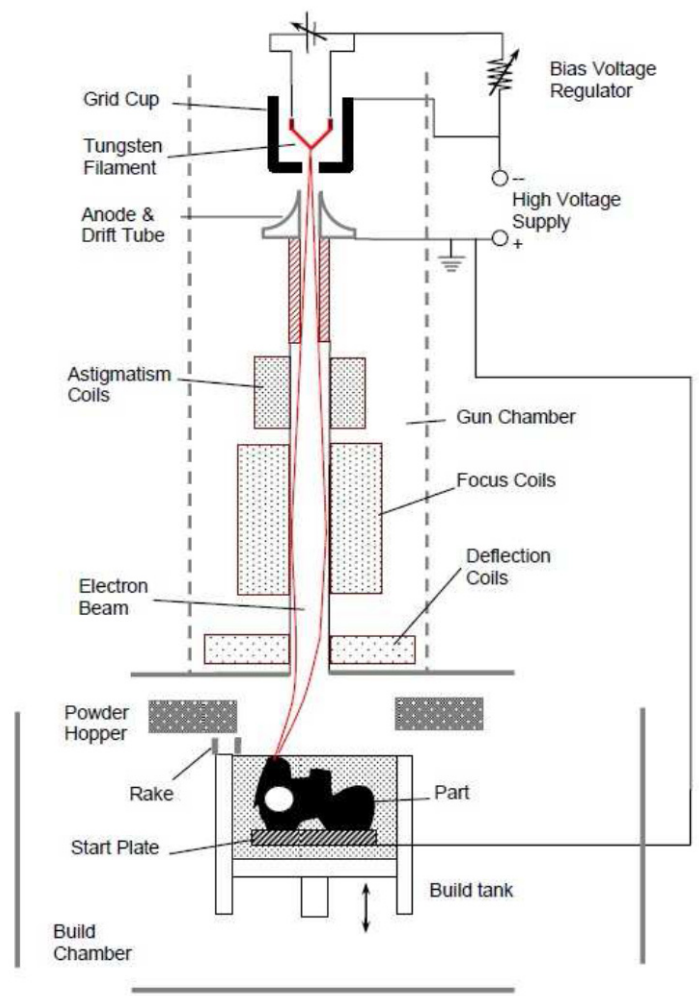

\section{Literature review}

Up to now, there is a lack of standards in $\mathrm{AM}$ and some investigations are still required to ensure the consistency and the quality of the parts. Errors sources of AM were categorised by Cooke and Soons (2010) in 3 groups:

1 Errors originating from the equipment, such as errors in the pattern generated by the energy beam due to errors in the scanning unit and optical aberrations, the energy distribution of the beam focus spot and its layer height.

2 Errors due to the process, such as spot diameter, layer thickness, thermal expansion of the part during deposition, warping of the part during cool down, melt pool deformation and sag of overhang structures into the supporting powder.

3 Errors in the part model due to the approximation of curved surfaces with planar triangular patches. 
One of the most important advantages of AM is the near net shape fabrication. If the final part is obtained from a rough part (by machining for example), there is a lot of waste but it is sure that the final part will be in the desired tolerances after finishing operations (machining) (Figure 3a). When the final part is obtained from an EBM rough part, there is less waste and a reduction of the machining time but it must fit the desired tolerances (Figure $3 b$ ). An efficient production of real near net shape parts requires a tight control of the process. In order to keep the advantages of AM, it is essential not to provide too large machining allowance, therefore the need to control them.

Figure 3 Machining operations are needed to obtain the final part. Comparison with (a) traditional raw material and (b) EBM raw material (see online version for colours)

\section{Conventional machining}

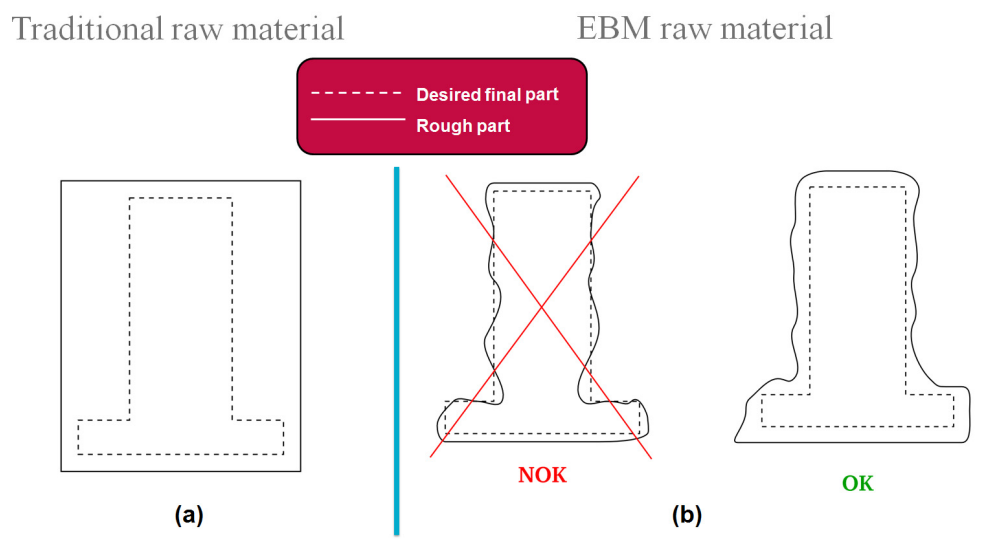

Several authors have proposed test artefacts to characterise the performance of additive processes. Moylan et al. (2012) did a ranking of some proposed tests to evaluate various aspects of the AM based on the literature. They highlighted four classes:

1 Test artefacts for processes comparison for decision making (Kruth, 1991; Lart, 1992; Childs and Juster, 1994; Jayaram et al., 1994; Ippolito et al., 1995; Xu et al., 2000; Campbell et al., 2002; Byun and Lee, 2003; Grimm, 2003; Mahesh et al., 2004; Mahesh et al., 2006; Kim and Oh, 2008; Brajlih et al., 2011; Robinson et al., 2010);

2 Test artefacts for individual process evaluation (Gargiulo, 1992; Bedal and Nguyen, 1996; Geiger et al., 1996; Dimitrov et al., 2003; Dimitrov et al., 2006; Hopkinson and Sercombe, 2008; Johnson et al., 2011; Senthilkumaran et al., 2011; Nguyen et al., 1992; Campanelli et al., 2007);

3 Test artefacts for metal-based processes evaluation (Cooke and Soons, 2010; Kruth et al., 2005; Castillo, 2005; Ning et al., 2006; Ghany and Moustafa, 2006; Hanumaiah and Ravi, 2007; Pessard et al., 2008; Delgado et al., 2010);

4 Test artefacts for other uses (Reddy et al., 2003; Armillotta, 2006; Es-Said et al., 2000; Vega et al., 2011). 
Figure 4 Solid model of the test artefact proposed by Moylan et al. (2012). Top view (left) and an oblique view (right)

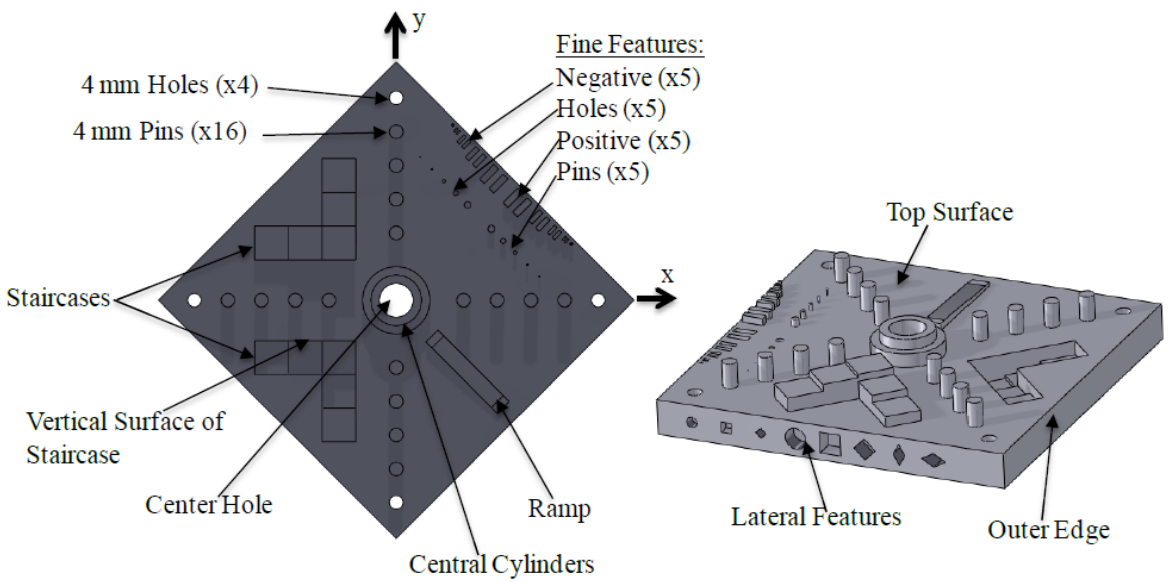

At the end of their work, they proposed a new test part for standardisation (see Figure 4). But up to now, all those studies were performed on a limited number of parts (1 to 5 maximum). Here we chose to produce a simple geometry in large numbers, all in the same fabrication batch (two batches were also performed to evaluate the reproducibility from one batch to another). The aim of our study is to further characterise the EBM process and determine the class of quality related to this process with different sizes of parts. To do this, a study of the dimensions obtained at the output of the process was carried out on a large number of parts.

This study is carried out in order to control finishing operations occurring after AM. EBM process is a near net shape process, not a net shape process. So it is needed to machine the part after EBM process (Figure 3). For machining the parts from the EBM process, dimensional tolerances of EBM process must be known. Moreover, the new trend for additive manufacturing is to develop series production. So it is imperative to define dimensional tolerances from the capabilities of this process.

\section{Materials and methods}

For the characterisation of the EBM process, the dimensional accuracy and the surface roughness were verified on a large number of parts (63 parts: 20 EPS1, 19 EPS2, 13 EPS3 and 11 EPS4) with 4 different sizes (see Table 1). These experiments were conducted after each batch of fabrication. This technique allows to determine the class of quality of the process and the repeatability of the results. The Arcam A2 EBM was used to build the samples. The material used in this study is the most used titanium alloy in the aeronautics industry: Ti6Al4V.

\subsection{Samples manufacturing}

These samples here named EPS were designed for tensile testing (their axis is along the Z building direction). For these parts, a set of standard parameters optimised for $70 \mu \mathrm{m}$ 
layers was used. As explained in Section 1, the process starts with preheating the powder then the contour melting and finally the inner region were melted (hatch melting). During fabrication, the temperature of the processed surface is maintained at $850^{\circ} \mathrm{C}$ by scanning the surface with the electron beam.

Figure 5 Tensile samples with different sizes

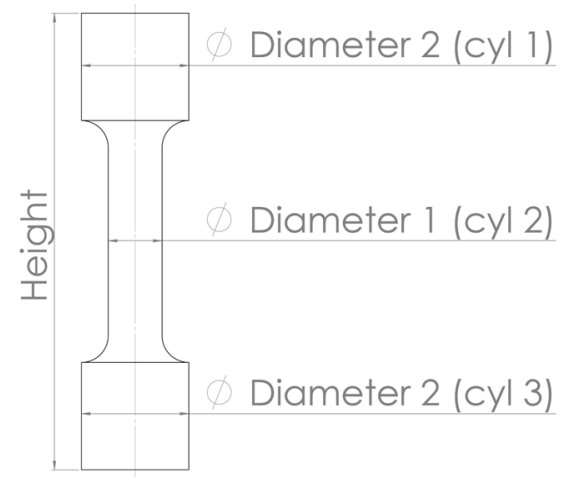

Table 1 A summary of the samples dimensions for the target values

\begin{tabular}{ccccc}
\hline$(\mathrm{mm})$ & Number of parts & Height & Diameter 2 & Diameter 1 \\
\hline EPS1 & 20 & 103.250 & 21.070 & 9.656 \\
EPS2 & 19 & 81.949 & 15.405 & 7.059 \\
EPS3 & 13 & 60.858 & 11.999 & 5.499 \\
EPS4 & 11 & 54.934 & 6.905 & 3.165 \\
\hline
\end{tabular}

The samples have four different dimensions with proportions kept according to ASTM E466 standard (ASTM, 2015). The dimensions were modified to evaluate (in another study) the impact on the properties caused by a variation of the samples dimensions. In addition, these samples are to be machined. So a machining allowance was added. Dimensions for the target values vary from 54.934 to $103.250 \mathrm{~mm}$ for the height and from 3.165 to $21.070 \mathrm{~mm}$ for the diameters. Table 1 present a summary of the sample dimensions. Twenty samples of each size were built at the same time, within the same fabrication batch. The position of each sample was recorded to check that the position of the sample in the batch of fabrication has no influence on the measured parameters.

The repeatability was also studied. For this purpose, two additional batches of fabrication were built. Batch 1 has 23 parts and batch 2 has 24 parts so 47 parts were studied. These samples have a cylindrical geometry (again the axis is along the $\mathrm{Z}$ direction (see Figures 2 and 5) and a diameter of $14.4 \mathrm{~mm}$. The purpose of this part of the study is to check the repeatability from a batch to another. To do this, a set of standard parameters optimised for $50 \mu \mathrm{m}$ layers was used.

The powder used in this study was Ti-6Al-4V spherical plasma atomised powder provided by Arcam, with a size distribution going typically from 45 to $106 \mu \mathrm{m}$ and centred around $70 \mu \mathrm{m}$. This powder is recycled with fresh additions of ELI (grade 23) powder. 


\subsection{Dimensional and surface characterisations}

For each batch of fabrication, the dimensions were determined using a coordinate measuring machine (Wenzel LH 54 precision: $\mathrm{Ux}, \mathrm{Uy}(\mu \mathrm{m})=3+10 . \mathrm{L} / 3$ and $\mathrm{Uz}(\mu \mathrm{m})=$ $3.5+10 . \mathrm{L} / 3)$. This technique uses a spherical probe to touch directly the part to define fundamental entities (plane, cylinder, etc.). The touch probe used for the measurements has a $2.5 \mathrm{~mm}$ diameter.

For the EPS samples the basic geometries were defined by (see Figure 6a):

- Plan: 6 points are touched uniformly along the plane;

- Cylinder: 8 points are touched uniformly along the half-cylinder.

And for the repeatability, the cylindrical samples were defined by this basic geometry (see Figure $6(b)$ ):

- Cylinder: 12 points are touched, 3 circles of 4 points along the cylinder.

Figure 6 Methodology of samples measurement: (a) EPS sample and (b) cylindrical samples (see online version for colours)

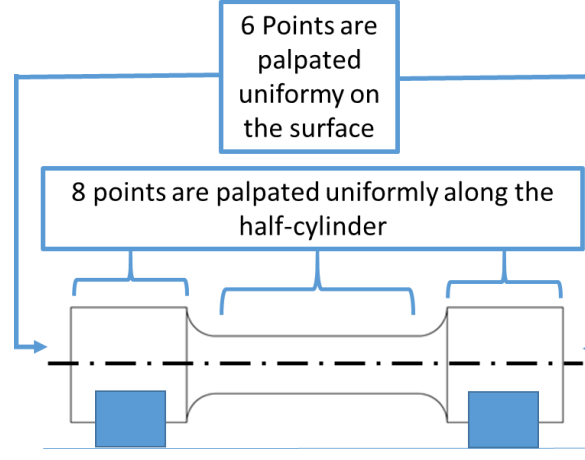

(a)

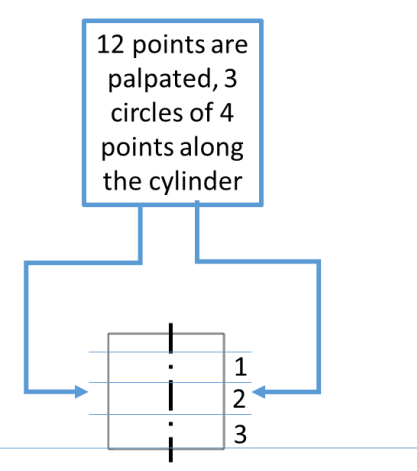

(b)

The measures were repeated three times for the cylindrical samples (repeatability study) and one time for EPS samples. The advantage of this method is the automation of the measurement. The diameters and the height of the samples were determined for each size of EPS samples. The diameters of the cylindrical samples were also measured.

Figure 7 Measure of the roughness on samples

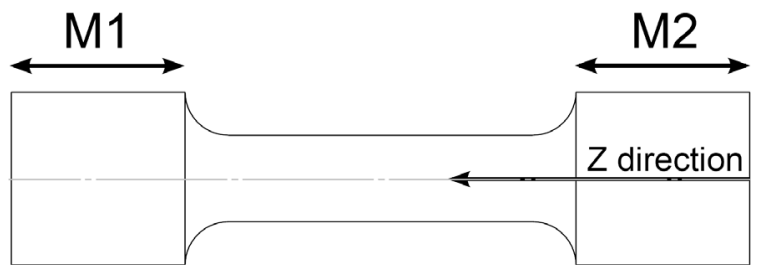


The surface quality was defined by a surface roughness meter SURFCOM 1400D-3DF. The ISO 4288 standard (ISO, 1996) was followed for each measurement. The measure was conducted along the build direction $(\mathrm{Z})$. Arithmetic roughness $(\mathrm{Ra})$ presented in this article is the average of $2 \mathrm{Ra}$ measurements (M1 and M2 on Figure 7) on each EPS sample. It should be noted that the evaluation length (ranging from 10 to $13 \mathrm{~mm}$ ) corresponds to the length of the larger section on the tensile samples and thus differs from the standard value $(5 \lambda=40 \mathrm{~mm})$.

\subsection{Capability approach}

According to Kapadia (2000), the capability is the long term performance level of a process after it has been brought under statistical control. It is the ability to produce a product that will consistently meet the design requirement and customer expectation.

Common indicators used in capability analysis $\left(C_{p}, C_{p u}, C_{p l}\right.$ and $\left.C_{p k}\right)$ were considered in this study. They are defined as follows (Mercier and Bergeret, 2011):

$C_{p}$ : Process capability for two-sided specification limit irrespective of process centre,

$$
C_{p}=\frac{U S L-L S L}{6 \sigma}
$$

$C_{p u}$ : Process capability relative to upper specification limit,

$$
C_{p u}=\frac{U S L-\bar{X}}{6 \sigma}
$$

$C_{p l}$ : Process capability relative to lower specification limit,

$$
C_{p l}=\frac{\bar{X}-L S L}{6 \sigma}
$$

$C_{p k}$ : Process capability for two-sided specification limit accounting for process centre,

$$
C_{p k}=\min \left(C_{p u}, C_{p l}\right)
$$

where

USL: Upper specification limit

LSL: Lower specification limit

$\bar{X}$ : Average value

$\sigma:$ Standard deviation.

A process is considered as capable if $C_{p k} \geq 1$. In this case, it means that the process produces less than 2700 non-conforming parts per million.

In this study, USL and $L S L$ were adopted by the Interval of Tolerances (IT) class (Boulanger, 2015) and the capability obtained was compared to the values announced by ARCAM (see www.arcam.com):

- $\quad \pm 0.13 \mathrm{~mm}$ if $D<30 \mathrm{~mm}$

- $\quad \pm 0.2 \mathrm{~mm}$ if $D \geq 30 \mathrm{~mm}$ 
where

$D$ : Dimension of the part.

Every processes is linked to an IT class, this method allows to compare the process with other processes in terms of dimensional quality.

\section{Results}

The results are presented in three steps. First, the dimensional characterisation of the samples is described. Then the surfaces analysis is developed. Finally, a capability study is conducted on these samples to determine the corresponding IT and compare it with other processes.

\subsection{Dimensional characterisation}

Figure 8 shows the repartition of the measures distribution for the height of the sample EPS1. The average value (plain line on Figure 8) is lower that the target value (dotted line on Figure 8). For the measure of the diameter (Figure 9), the trend is opposite. The average value is larger than the target value. It should be noted that the length measurements are made in the build direction ( $\mathrm{Z}$ axis) and the diameter measurements are made in the $\mathrm{XY}$ direction.

Figure 8 Distribution of measured values for the height of EPS1 (see online version for colours)

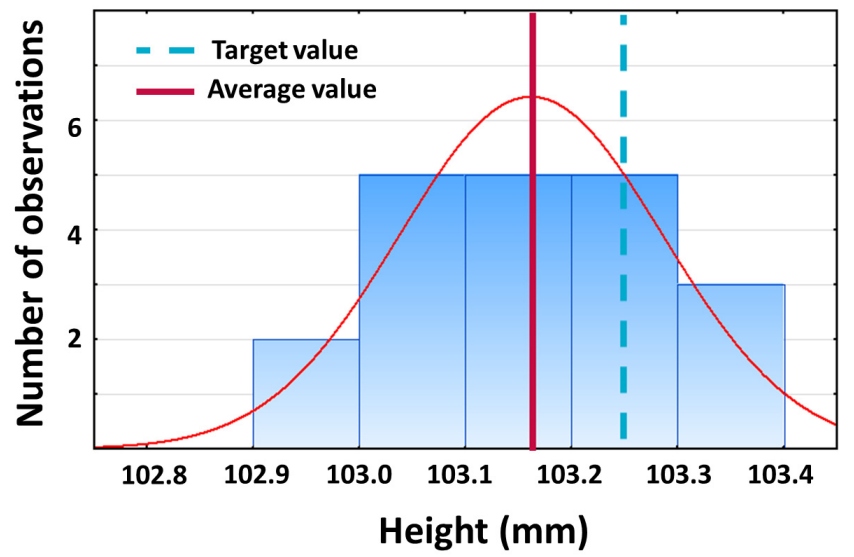

These observations are repeated for all sizes and geometries considered. A summary of the samples and the parameters used are presented in Table 2. It is therefore possible to summarise the configurations. Figure 10 depicts the trend of the distribution obtained along the direction $\mathrm{Z}$ and Figure 11 the trend of the distribution obtained along the direction $\mathrm{XY}$. 
Figure 9 Distribution of measured values for diameter 2 (see Figure 5 and Table 1 of EPS1) (see online version for colours)

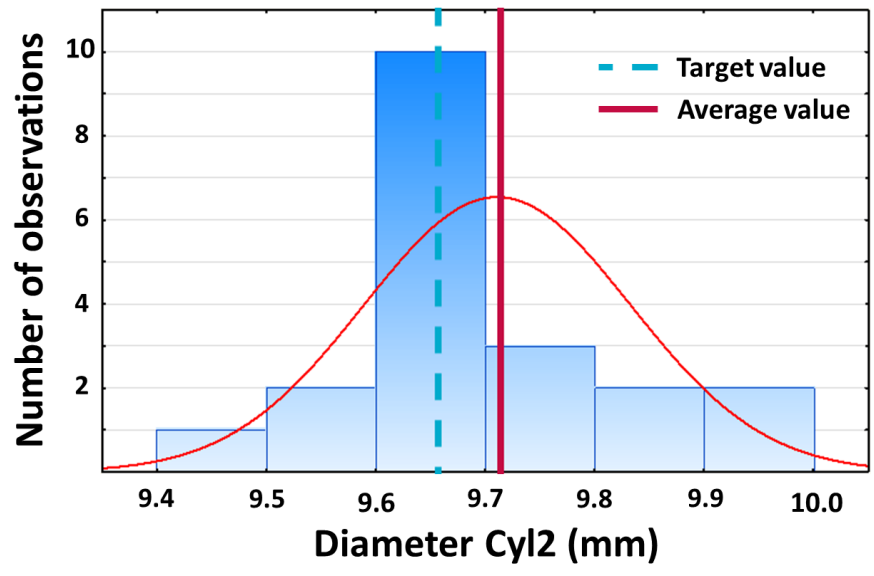

Table 2 A summary of the measures for all the samples

\begin{tabular}{cccccc}
\hline & & Number of parts & Target value $(\mathrm{mm})$ & Systematic error $(\mathrm{mm})$ & $\sigma(\mathrm{mm})$ \\
\hline \multirow{4}{*}{ EPS 1 } & Length & 20 & 103.250 & -0.088 & 0.124 \\
& cyl1 & 20 & 21.070 & +0.087 & 0.104 \\
& cyl2 & 20 & 9.656 & +0.055 & 0.122 \\
& cyl3 & 20 & 21.070 & +0.008 & 0.067 \\
\hline \multirow{5}{*}{ EPS 2 } & Length & 19 & 81.949 & -0.568 & 0.114 \\
& cyl1 & 19 & 15.405 & +0.060 & 0.055 \\
& cyl2 & 19 & 7.059 & +0.099 & 0.089 \\
\multirow{5}{*}{ EPS 3 } & cyl3 & 19 & 15.405 & +0.037 & 0.068 \\
& Length & 13 & 60.858 & -0.502 & 0.075 \\
& cyl1 & 13 & 11.999 & +0.108 & 0.083 \\
& cyl2 & 13 & 5.498 & +0.017 & 0.024 \\
& cyl3 & 13 & 11.999 & +0.107 & 0.094 \\
\hline \multirow{5}{*}{ EPS 4 } & Length & 11 & 54.934 & -0.054 & 0.105 \\
& cyl1 & 11 & 6.905 & +0.031 & 0.059 \\
& cyl2 & 11 & 3.165 & +0.118 & 0.130 \\
& cyl3 & 11 & 6.905 & +0.016 & 0.081 \\
\hline
\end{tabular}

Figures 10 and 11 show that random error as well as systematic error are found. The random error is related to the process but not the systematic one. The systematic error varies according to the axes considered ( $\mathrm{Z}$ and $\mathrm{XY}$ directions). This error may depend on the calibration of the machine. Those very systematic small deviations are indeed most probably arising from different causes such as for instance imperfect table motor calibration for the $\mathrm{Z}$ direction. Once established, they can be suppressed by applying a dilatation factor to the $\mathrm{CAD}$ file (in the $\mathrm{XY}$ plan and another in the $\mathrm{Z}$ direction). 
Figure 10 Trends of the distribution of the measured value along $\mathrm{Z}$ direction (Height) for EPS samples (see online version for colours)

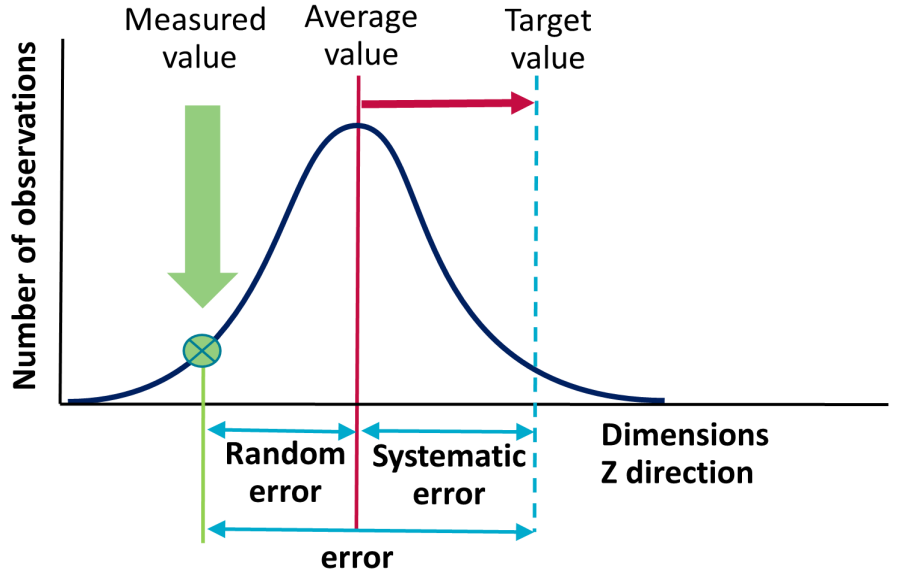

Figure 11 Trends of the distribution of the measured value along XY direction (Diameter) for EPS samples (see online version for colours)

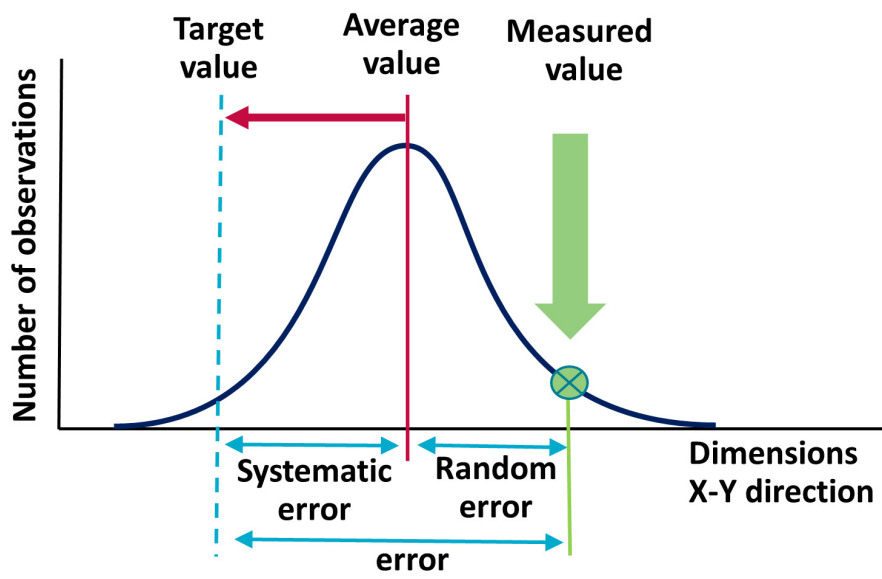

To assert the repeatability a second set of measurements was thus conducted on cylindrical samples batches printed several times. The same trend is found on Figure 12 for the two batches. The average value was larger than the target value (by about the same amount) as for the previous EPS samples analysis (Figure 11) for XY direction. That means that the process is consistent over the 3 batches reported in this article.

\subsection{Surface roughness}

Figure 13 shows the Ra obtained on EPS1. All the values are a bit larger than $25 \mu \mathrm{m}$ excepted for sample I. The comparison of the average values is presented on Table 4, it highlights that every average values are above $25 \mu \mathrm{m}$. Yet, these values are close to those announced by $\operatorname{ARCAM}(\mathrm{Ra}=25 \mu \mathrm{m})$ (see www.arcam.com). 
Figure 12 Distribution of the measured value along XY direction (Diameter) for batch 2 for the repeatability samples (see online version for colours)

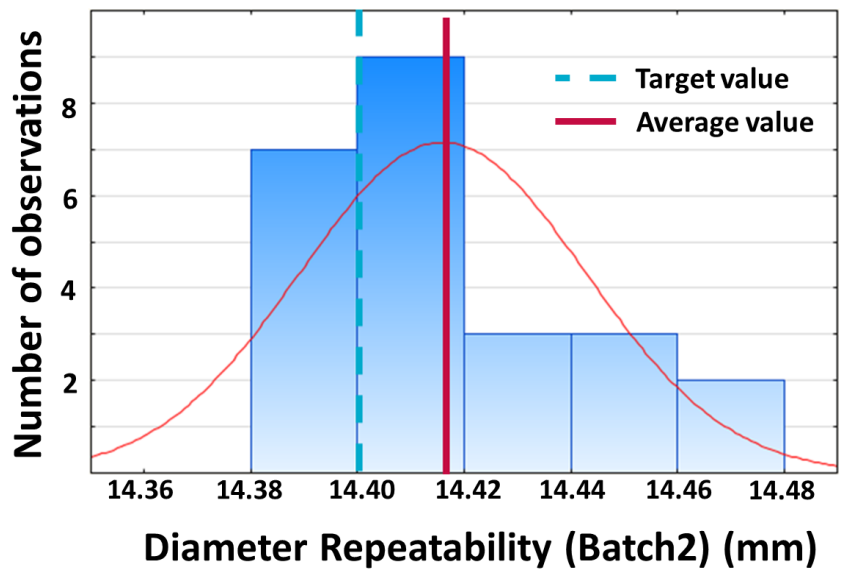

Table 3 A summary of the measured values (XY direction) for all the repeatability samples

\begin{tabular}{lccccc}
\hline & Batch & $\begin{array}{c}\text { Number of } \\
\text { parts }\end{array}$ & $\begin{array}{c}\text { Target value } \\
(\mathrm{mm})\end{array}$ & $\begin{array}{c}\text { Systematic error } \\
(\mathrm{mm})\end{array}$ & $\begin{array}{c}\sigma \\
(\mathrm{mm})\end{array}$ \\
\hline \multirow{2}{*}{ Repeatability part } & batch 1 & 23 & 14.400 & +0.005 & 0.125 \\
& batch 2 & 24 & 14.400 & +0.016 & 0.161 \\
\hline
\end{tabular}

Figure 13 Surface roughness (Ra value) measured on EPS1 (average value is the plain line on the diagram) (see online version for colours)

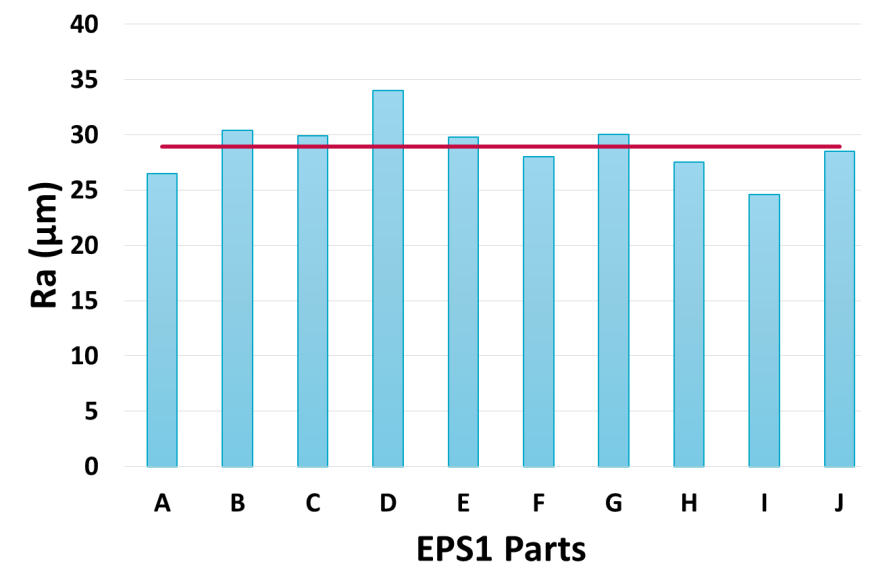


Table 4 A summary of the surface roughness (Ra value) measured for all the samples

\begin{tabular}{cccc}
\hline Ra $(\mu \mathrm{m})$ & Average values $M 1$ & Average values $M 2$ & Average Values $(M 1$ and $M 2)$ \\
\hline EPS 1 & 29.53 & 28.33 & 28.93 \\
EPS 2 & 25.07 & 26.81 & 25.94 \\
EPS 3 & 31.47 & 28.78 & 30.12 \\
EPS 4 & 27.90 & 27.26 & 27.58 \\
\hline
\end{tabular}

\subsection{Capability analysis, correspondence IT and comparison with other processes}

A study of the capability was conducted on EPS1 and EPS2 samples. The capability analysis carried out on the diameter of EPS1 (Figure 14) showed that the process capability is statistically guaranteed for an IT 15 (see Table 5). The same trend was observed for the other dimensions (except IT 16 for EPS2 Cyl2 see Table 5).

Figure 14 Evolution of the capability depending of the IT class for EPS1 diameter (plain line is the capability limit)

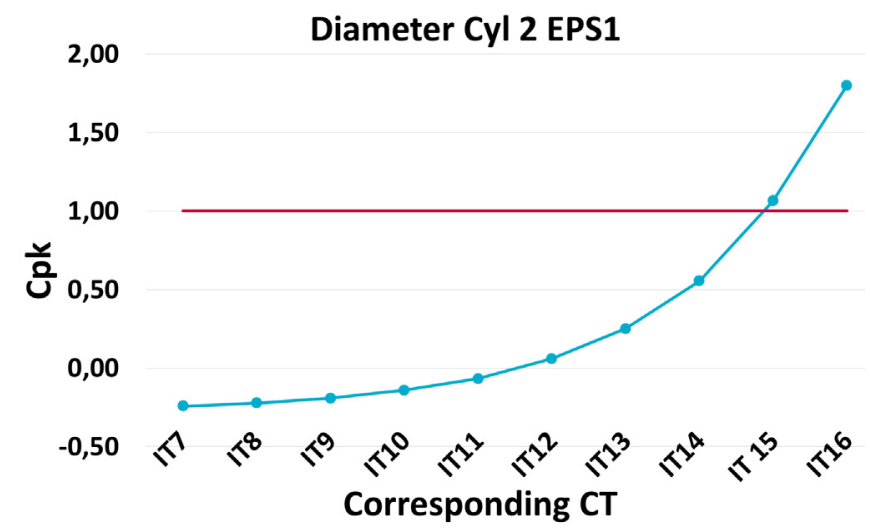

Table 5 A summary of the capability depending of the IT class

\begin{tabular}{ccccccccc}
\hline$C_{p k}$ & & $I T 11$ & $I T 12$ & $I T 13$ & IT14 & IT15 & IT16 & ARCAM \\
\hline \multirow{2}{*}{ EPS1 } & Height & 0.06 & 0.23 & 0.49 & 0.93 & 1.64 & 2.72 & 0.30 \\
& Cy12 & -0.07 & 0.06 & 0.25 & 0.55 & 1.07 & 1.80 & 0.14 \\
\hline \multirow{2}{*}{ EPS2 } & Height & -1.39 & -1.19 & -0.91 & -0.41 & 0.39 & 1.59 & -1.12 \\
& Cy12 & -0.01 & 0.20 & 0.47 & 0.96 & 1.77 & 2.98 & 0.44 \\
\hline
\end{tabular}

\section{Discussions}

It is difficult to draw conclusions for the roughness measurement. The results are indeed quite dispersed. We still find values close to those of the literature $(\mathrm{Ra}=25 \mu \mathrm{m})$. If the goal of the process is to reach mechanical applications such as contact, the surface of the 
part needs to be machined to obtain typical values $\mathrm{Ra}=0.1 \mu \mathrm{m}$ (Boulanger, 2015). However, the high surface roughness can be an advantage in application such as osseointegration (Bertollo et al., 2012).

The dimensional characterisation shows that the error is composed of a random error and a systematic error. The random error is the error related to the EBM process. It is also noticed that the systematic error depends on the direction (XY direction and $\mathrm{Z}$ direction). With this error, the IT class of the process is IT15 - IT16. To improve it, the average value must be as close as possible to the target value. This difference depends on the calibration of the machine. If only $\sigma$ is considered (Table 2 and Table 3 ) for the determination of IT class (IT $=6 \sigma$ ), the IT class may decrease significantly to IT12.

An IT12 class corresponds to the sand casting process but this is really less flexible. Moreover the correction of the geometry during the mass production induces additional costs.

The machining allowance can be defined in the same way as sand casting process $(0.5 \mathrm{~mm} \pm 1 / 2$ IT (ISO, 1994)). The only way to decrease the machining allowance is to decrease the IT class. The machining allowance could therefore be smaller if the average value and the target value get closer.

Table $6100 \mathrm{~mm}$ side cube with different class of tolerance $\left(V_{i}=\right.$ rough volume and $V_{f}=$ volume after machining)

\begin{tabular}{cccc}
\hline & Tolerance $(\mu \mathrm{m})$ & Edge $(\mathrm{mm})$ & $\frac{V_{f}-V_{i}}{V_{i}}(\%)$ \\
\hline IT10 & 140 & 100.57 & 1.72 \\
IT11 & 220 & 100.61 & 1.84 \\
IT12 & 350 & 100.675 & 2.04 \\
IT13 & 540 & 100.77 & 2.33 \\
IT14 & 870 & 100.935 & 2.83 \\
IT15 & 1400 & 101.2 & 3.64 \\
IT16 & 2200 & 101.6 & 4.88 \\
\hline
\end{tabular}

To highlight the importance of controlling the process, Table 6 is the variation of the machining allowance for a $100 \mathrm{mn}$ side cube with different classes of tolerance. If the IT class could decreases from IT 15 to IT 12 by avoiding the systematic errors, $16,047 \mathrm{~mm}^{3}$ less waste will be produced $(2 \%)$.

Another example, with a smaller part, is the fabrication of a cylinder with a diameter of $10 \mathrm{~mm}$ and a height of $10 \mathrm{~mm}$. Table 7 is the variation of machining allowance for this case. This result highlights the impact of machining allowance that is much more impacting on small parts.

Table 7 shows that the machining allowance for the fabrication of the cylinder represent $26.62 \%$ of the total volume of the part. By avoiding the systematic errors, the machining allowance represents $18.26 \%$ of the total volume of the part. So, it is important to determine the class of tolerance of the EBM Process especially for serial part production. 
Table 7 Cylinder with a diameter of $10 \mathrm{~mm}$ and the height of $10 \mathrm{~mm}$ with different class of tolerance $\left(V_{i}=\right.$ rough volume and $V_{f}=$ volume after machining $)$

\begin{tabular}{cccc}
\hline & Tolerance $(\mu \mathrm{m})$ & Edge $(\mathrm{mm})$ & $\frac{V_{f}-V_{i}}{V_{i}}(\%)$ \\
\hline IT10 & 58 & 10.529 & 16.72 \\
IT11 & 90 & 10.545 & 17.26 \\
IT12 & 150 & 10.575 & 18.26 \\
IT13 & 220 & 10.61 & 19.44 \\
IT14 & 360 & 10.68 & 21.82 \\
IT15 & 580 & 10.79 & 25.62 \\
IT16 & 900 & 10.95 & 31.29 \\
\hline
\end{tabular}

\section{Conclusions}

The study conducted is a first step of the EBM characterisation with a view to mass production. The statistical analysis of an EBM production is not widespread yet. The final goal of EBM process is to manufacture high-added-value parts with a strong flexibility. The production costs will inevitably influence the development of the use of EBM process for mass production. To decrease these costs, the definition of machining allowances as small as possible is desirable, especially for thin parts production. In this study, the roughness of 40 parts and the dimensions of 110 were measured. A capability analysis was carried out. In our case, the EBM process was found consistent with a class of tolerance IT15 and with simple precaution to cancel systematic errors due to imperfect calibration, an IT12 could even be achieved. The surface roughness of the samples measured was close to the value announced by ARCAM with a $\mathrm{Ra}=25 \mu \mathrm{m}$ (see www.arcam.com).

\section{References}

Armillotta, A. (2006) 'Assessment of surface quality on textured FDM prototypes', Rapid Prototyping Journal, Vol. 12, No. 1, pp.35-41.

ASTM (2015) E466 - 15 - Standard Practice for Conducting Force Controlled Constant Amplitude Axial Fatigue Tests of Metallic Materials, ASTM International.

Bertollo, N., Assuncao, E.D. Hancock, N.J., Lau, A. and Walsh, W.R. (2012) 'Influence of electron beam melting manufactured implants on ingrowth and shear strength in an ovine model', The Journal of Arthroplasty, Vol. 27, No. 8, pp.1429-1436.

Byun, H.S. and Lee, K. (2003) 'Design of a new test part for benchmarking the accuracy and surface finish of rapid prototyping processes', Computational Science and Its Applications ICCSA2003, pp.989-989.

Bedal, B. and Nguyen, H. (1996) 'Advances in part accuracy', Stereolithography and Other RP\&M Processes, American Society of Mechanical Engineers, pp.149-182.

Boulanger, J. (2015) Tolérances et écarts dimensionnels, géométriques et d'états de surface Techniques de l'ingénieur [Archives] Travail des métaux - Assemblage, base documentaire: TIBabtDUO (ref. article: b7010). 
Brajlih, T., Valentan, B., Balic, J. and Drstvensek, I. (2011) 'Speed accuracy evaluation of additive manufacturing machines', Rapid Prototyping Journal, Vol. 17, No. 1, pp.64-75.

Castillo, L. (2005) Study about the rapid manufacturing of complex parts of stainless steel and titanium, Technical report.

Campanelli, S.L., Cardano, G., Giannoccaro, R., Ludovico, A.D. and Bohez, E.L.J. (2007) 'Statistical analysis of the stereolithographic process to improve the accuracy', ComputerAided Design, Vol. 39, No. 1, pp.80-86.

Childs, T.H.C. and Juster, N.P. (1994) 'Linear and geometric accuracies from layer manufacturing', CIRP Annals - Manufacturing Technology, Vol. 43, No. 1, pp.163-166.

Campbell, R.I., Martorelli, M. and Lee, H.S. (2002) 'Surface roughness visualization for rapid prototyping models', Computer-Aided Design, Vol. 34, pp.717-715.

Delgado, J., Ciurana, J., Reguant, C. and Cavallini, B. (2010) Studying the repeatability in dmls technology using a complete geometry test part, Technical report.

Dimitrov, D., van Wijck, W., Schrevel, K., de Beer, N. and Meijer, J. (2003) 'An investigation of the capability profile of the three dimensional printing process with an emphasis on the achievable accuracy', CIRP Annals, Vol. 52, No. 1, pp.189-192.

Dimitrov, D., van Wijck, W., Schrevel, K. and de Beer, N. (2006) 'Investigating the achievable accuracy of three dimensional printing', Rapid Prototyping Journal, Vol. 12, No. 1, pp.42-52.

Es-Said, O.S., Foyos, J., Noorani, R., Mendelson, M., Marloth, R. and Pregger, B.A. (2000) 'Effect of layer orientation on mechanical properties of rapid prototyped samples', Materials and Manufacturing Processes, Vol. 15, No. 1, pp.107-122.

Mercier, S. and Bergeret, F. (2011) Maîtrise statistique des procédés: Principes et cas industriels, Dunod/Usine Nouvelle.

Farhat, D. and Engel, C. (2012) 'Novel and promising free form manufacturing technology contribute to the improvement of a trapezo-metacarpal joint implant', 17th European Forum on Rapid Prototyping and Manufacturing.

$\mathrm{Xu}$, F., Wong, Y.S. and Loh, H.T. (2000) 'Toward generic model for comparative evaluation and process selection in rapid prototyping and manufacturing', Journal of Manufacturing Systems, Vol. 19, No. 5, pp.283-296.

Gargiulo, E.P. (1992) 'Stereolithography process accuracy: user experience', Proceedings of the 1st European Conference on Rapid Prototyping, University of Nottingham, pp.187-207.

Geiger, M., Coremans, A., Neubauer, N. and Niebling, F. (1996) 'Advanced rapid prototyping by laser beam sintering of metal prototypes: design and development of an optimized laser beam delivery system', Proceedings of SPIE 2787, pp.103-114.

Ghany, K.A. and Moustafa, S.F. (2006) 'Comparison between the products of four rpm systems for metals', Rapid Prototyping Journal, Vol. 12, No. 2, pp.86-94.

Grimm, T. (2003) Rapid Prototyping Benchmark 3D Printers, T.A. Grimm \& Associates, Inc.

Hanumaiah, N. and Ravi, B. (2007) 'Rapid tooling form accuracy estimation using region elimination adaptive search based sampling technique', Rapid Prototyping Journal, Vol. 13, No. 3, pp.182-190.

Hopkinson, N. and Sercombe, T.B. (2008) 'Process repeatability and sources of error in indirect sls of aluminium', Rapid Prototyping Journal, Vol. 14, No. 2, pp.108-113.

Ippolito, R., Iuliano, L. and Gatto, A. (1995) 'Benchmarking of rapid prototyping techniques in terms of dimensional accuracy and surface finish', CIRP Annals - Manufacturing Technology, Vol. 44, No. 1, pp.157-160.

ISO (1994) Norme ISO 8062 - Pièces moulées - Système de tolérances dimensionnelles.

ISO (1996) International standards ISO 4288 (1996) - Geometrical Product Specifications (GPS) Surface texture: Profile method-Rules and procedures for the assessment of surface texture.

Jayaram, D., Bagchi, A., Jara-Almonte, C.C. and O'Reilly, S. (1994) 'Benchmarking of rapid prototyping systems - beginning to set standards', Proceedings of the Solid Freeform Fabrication Symposium, pp.146-153. 
Johnson, W.M., Rowell, M., Deason, B. and Eubanks, M. (2011) 'Benchmarking evaluation of an open source fused deposition modeling', Additive Manufacturing System, 2011.

Kapadia, M. (2000) Measuring your process capability, Technical report, Symphony technologies.

Kim, G.D. and Oh, Y.T. (2008) 'A benchmark stud on rapid prototyping processes and machines: quantitative comparison of mechanical properties, accuracy, roughness, speed and material cost', Proceedings of the institution of mechanical engineers Journal of Engineering Manufacture, Vol. 222, No. 2, pp.201-215.

Kruth, J.P. (1991) 'Material incress manufacturing by rapid prototyping techniques', CIRP Annals - Manufacturing Technology, Vol. 40, No. 2, pp.603-614.

Kruth, J.-P.V., Van Vaerenbergh, B. and Mercelis, J. (2005) 'Benchmarking of different sls/slm processes as rapid manufacturing techniques', International Conference of Polymers \& Moulds Innovations (PMI).

Lart, G. (1992) 'Comparison of rapid prototyping systems', Proceedings of 1st European Conference on Rapid Prototyping, University of Nottingham, UK, pp.243-254.

Cooke, A.L. and Soons, J.A. (2010) 'Variability in the geometric accuracy of additive manufactured test part', 21st Annual Solid Freeform Fabrication Symposium Conference Paper, 2010.

Mahale, T.R. (2009) Electron Beam Melting of Advanced Materials and Structures, PhD Thesis, Faculty of North Carolina State University.

Moylan, S.P., Slotwinski, J.A., Cooke, A.L., Jurrens, K.K. and Donmez, M.A. (2012) 'Proposal for a standardized test artifact for additive manufacturing machines and processes', Proceedings of the Solid Freeform Fabrication Symposium, 6-8 August.

Monfort-Windels, F. (2013) Evolution des techniques de fabrication additive, Sirris, Juillet.

Mahesh, M., Wong, Y., Fuh, J.Y.H. and Loh, H.T. (2004) 'Benchmarking for comparative evaluation of rp systems and processes', Rapid Prototyping Journal, Vol. 10, No. 2, pp.123-135.

Mahesh, M., Wong, Y., Fuh, J.Y.H. and Loh, H.T. (2006) 'A six-sigma approach for benchmarking of rp\&m processes', International Journal of Advanced Manufacturing Technology, Vol. 31, Nos. 3/4, pp.374-387.

Nguyen, H., Richter, J. and Jacobs, P. (1992) 'On windowpanes and christmas-trees: diagnostic techniques for improved part accuracy', 3rd International Conference on Rapid Prototyping, pp.41-62.

Ning, Y., Wong, Y.S., Fuh, J.Y.H. and Loh, H.T. (2006) 'An approach to minimize build errors in direct metal laser sintering', IEEE Transactions on Automation Science and Engineering, Vol. 3, No. 1, pp.73-80.

Pessard, E., Mognol, P., Hascoet, J.Y. and Gerometta, C. (2008) 'Complex cast parts with rapid tooling: rapid manufacturing point of view', International Journal of Advanced Manufacturing Technology, Vol. 39, Nos. 9/10, pp.898-904.

Reddy, N.V., Pandey, P.M. and Dhande, S.G. (2003) 'Improvement of surface finish by staircase machining in fused deposition modeling', Journal of Materials Processing Technology, Vol. 132, Nos. 1-3, pp.323-331.

Robinson, C.C., Morris, G. and Brown, R. (2010) Rare parts through RM\&R. Available online at: http://www.ncms.org/wp-content/NCMS_files/CTMA/Symposium2010/Presentations/Wed_ manf/O200_RARE_Parts.pdf (accessed in August 2015).

Senthilkumaran, K., Pandey, P.M. and Rao, P. (2011) 'Statistical modeling and minimization of form error in SLS prototyping', Rapid Prototyping Journal, Vol. 18, No. 1.

Vega, V., Clements, J., Lam, T., Abad, A., Fritz, B., Ula, N. and Es-Said, O.S. (2011) 'The effect of layer orientation on the mechanical properties and microstructure of a polymer', Journal of Materials Engineering and Performance, Vol. 20, No. 6, pp.978-988.

Vutova, K., Vassileva, V., Koleva, E., Georgieva, E., Mladenov, G., Mollov, D. and Kardjiev, M. (2010) 'Investigation of electron beam melting and refining of titanium and tantalum scrap', Journal of Materials Processing Technology, Vol. 210, No. 8, pp.1089-1094. 